\title{
DESIGNING FUZZY LOGIC CONTROLLER FOR INVERTED PENDULUM
}

\author{
Haresh A. Suthar and Kaushal B. Pandya \\ Sardar Vallabhbhai Patel Institute of Technology, VASAD. Dist. Anand, Gujarat, India.
}

\begin{abstract}
In control system, if all the states of the system are measured, then by using state feedback control law we can control the system. As we know that value of feedback gain cannot be found easily, it requires trial and error method for suitable pole locations. In certain applications state variables cannot be measured because of cost considerations or lack of suitable transducers. In such cases, state variables that cannot be measured must be estimated from the ones that are measurable. A device, which estimates states, is known as 'observer' or 'state observer'. To design observer, person has to face mathematical complexities. Here without facing mathematical complexities control system can be controlled using Fuzzy Logic Approach.
\end{abstract}

\section{INTRODUCTION}

We have considered the problem of Inverted Pendulum, which is hinged to a moving cart; the main objective is to keep pendulum vertical and cart in its initial position irrespective of disturbances. Considering all the parameters involved in the problem the differential equations describing dynamics of the inverted pendulum and the cart are derived. System is simulated in MATLAB SIMULINK. Using Fuzzy Logic Toolbox in MATLAB system is controlled and satisfactory results are obtained.

\section{PROBLEM OF INVERTED PENDULUM}

The problem of stabilization of an inverted pendulum on a cart is considered.. The following Figure-1 Shows an Inverted pendulum with its pivot mounted on a cart. An external force drives the cart. The external force drives a pair of wheels of the cart. The force at a time $t$ exerts a Torque $T(t)$ on the wheels. The linear force applied to the cart is $u(t) ; T(t)=R u(t)$ 
where, $\mathrm{R}$ is radius of the wheels.

The pendulum is unstable, but be kept upright by applying a proper control force $u(t)$.

The dynamics of the inverted pendulum and the cart are described by the equations $1 \& 2$.

$$
\begin{aligned}
& \ddot{\theta}(t)=\frac{m l(M+m) g}{\Delta} \theta(t)-\frac{m l}{\Delta} u(t) \\
& \ddot{z}(t)=\frac{m^{2} l^{2} g}{\Delta} \theta(t)+\frac{\left(J+m l^{2}\right)}{\Delta} u(t)
\end{aligned}
$$

Where,

Horizontal displacement of the pivot on the cart is $\mathrm{z}(\mathrm{t})$,

Rotational angle of the pendulum is $\theta(t)$.

The parameters of the system are as follows.

$\mathrm{M}=$ the mass of the cart,

$\mathrm{L}=$ length of the pendulum $=2 \times 1$,

$\mathrm{m}=$ the mass of pendulum and

$\mathrm{J}=$ the moment of inertia of pendulum with respect to center of gravity

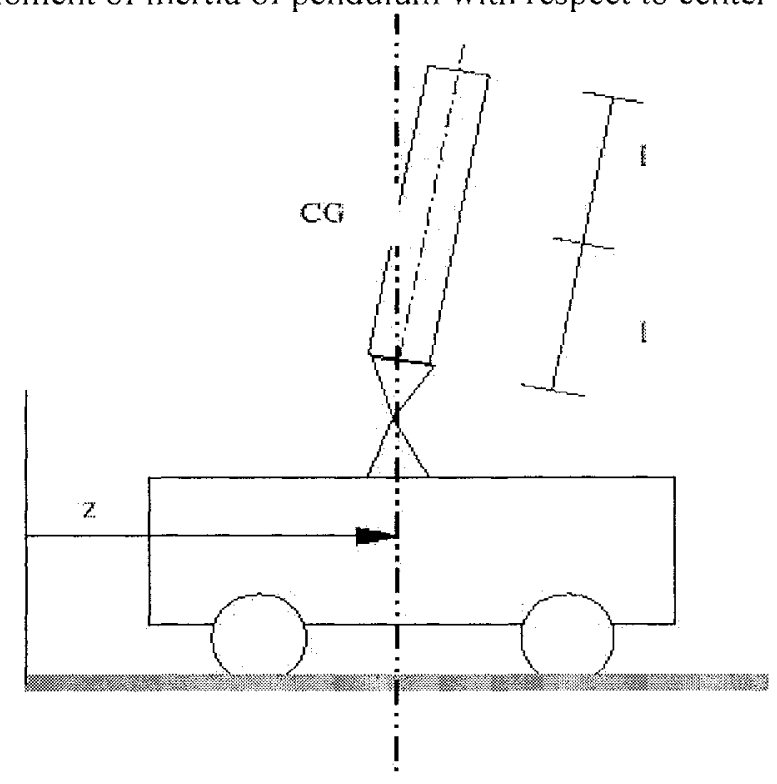

Figure-1: Inverted Pendulum System

Suppose that system parameters are $M=1 \mathrm{~kg}, \mathrm{~m}=0.15 \mathrm{~kg}, l=1 \mathrm{~m}$. Recall that $\mathrm{g}=9.81 \mathrm{~m} / \mathrm{sec}^{2}$.

$$
J=\frac{1}{3} m L^{2}=\frac{4}{3} m l^{2}=0.2 k g-m^{2}
$$




$$
\begin{aligned}
& \ddot{\theta}(t)=4.4537 \theta(\mathrm{t})-0.3947 \mathrm{u}(\mathrm{t}) \quad \ldots 3 \\
& \ddot{z}(t)=-0.5809 \theta(\mathrm{t})+0.9211 \mathrm{u}(\mathrm{t})
\end{aligned}
$$
obtain the following state model for the inverted pendulum on moving cart. $\dot{X}=A X+B u$

$$
A=\left[\begin{array}{cccc}
0 & 1 & 0 & 0 \\
4.4537 & 0 & 0 & 0 \\
0 & 0 & 0 & 1 \\
-0.5809 & 0 & 0 & 0
\end{array}\right] \quad B=\left[\begin{array}{c}
0 \\
-0.3947 \\
0 \\
0.9211
\end{array}\right]
$$

The corresponding discrete state model of the above system is as under: $X(k+1)=A X(k)+B u(k)$

where,

$$
A=\left[\begin{array}{cccc}
1.0009 & 0.020006 & 0 & 0 \\
0.0891 & 1.0009 & 0 & 0 \\
-0.0001162 & -7.746 e-07 & 1 & 0.02 \\
-0.011621 & -0.0001162 & 0 & 1
\end{array}\right] \quad B=\left[\begin{array}{c}
-7.8952 e-005 \\
-0.0078963 \\
0.00018422 \\
0.018422
\end{array}\right]
$$

Move the cart from one location to another without causing pendulum to fall $\ldots$

\section{PROBLEM SOLUTION}

As shown in Figure-2, when we apply disturbance signal to the system four state variables i.e. angle, rate of change of angle, distance traversed by the cart and velocity of the cart will be generated. At any instant $k$, the input to the system is $u(k)$; and generated four state variables are $\theta(k), \dot{\theta}(k), z(k)$ and $\dot{z}(k)$. Two state variables $\theta(k)$ and $\dot{\theta}(k)$ are given to the fuzzy controller. Fuzzy controller generates next required velocity of the cart i.e. $z(k+1)$ 


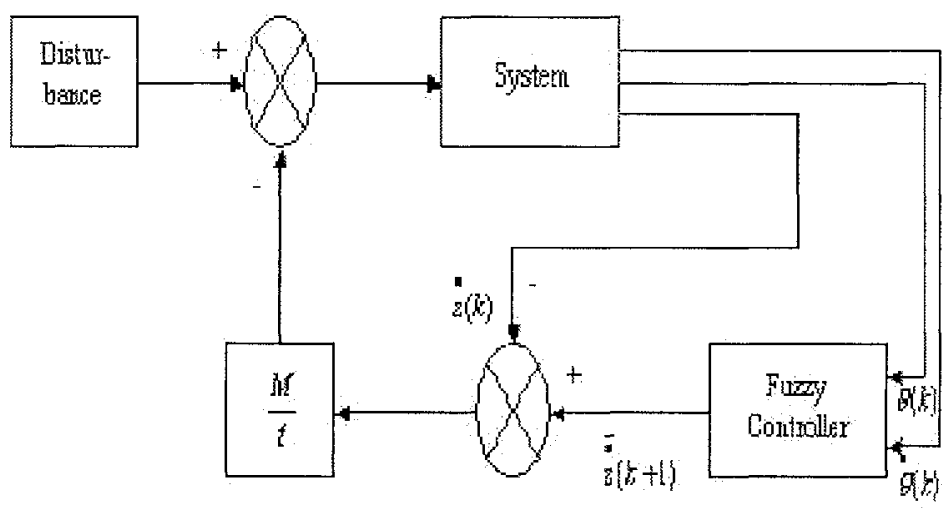

Figure 2; Block Diagram

$z(k+1)$ can be obtained by applying proper force to the system i.e. $\bar{u}(k+1)$. Where,

$$
\begin{aligned}
\vec{u}(k+1) & =M \times \ddot{\bar{z}}(k+1) \\
& =M \times\left[\frac{\dot{\vec{z}}(k+1)-\dot{z}(k)}{t}\right]
\end{aligned}
$$

$\mathrm{t}=$ time in which $z(k+1)$ is to be obtained.

Now it is required to design a Fuzzy Controller that can be done using FIS Editor in MATLAB.

\section{DESIGN OF FUZZY CONTROLLER USING FIS EDITOR}

As discussed in above block diagram, angle and rate of change of angle $(\theta(k)$ and $\dot{\theta}(k))$ are the selected inputs of the Mamdani type of fuzzy controller -

and next required velocity of the cart $(z(k+1))$ is the output. Two input variables and one output variable along with their fuzzy levels and membership functions are as shown in the following Figure-3. 


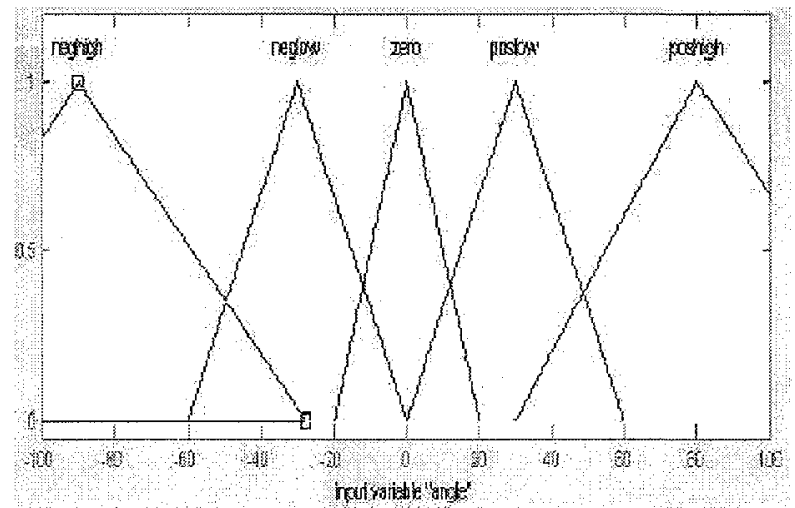

(a)

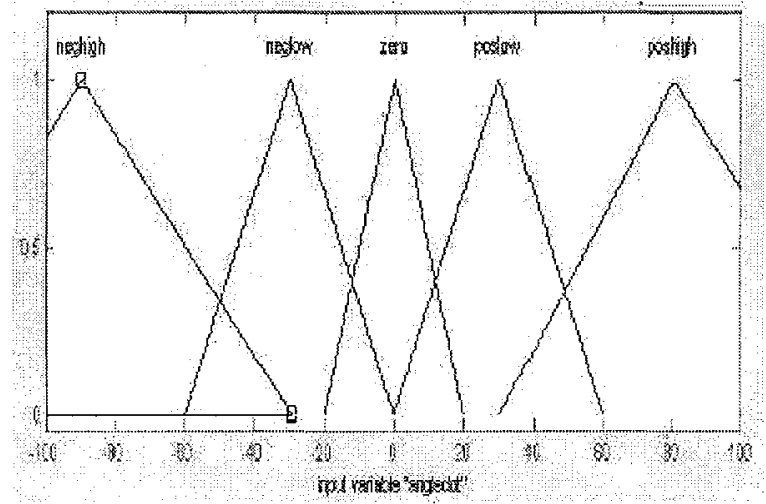

(b)

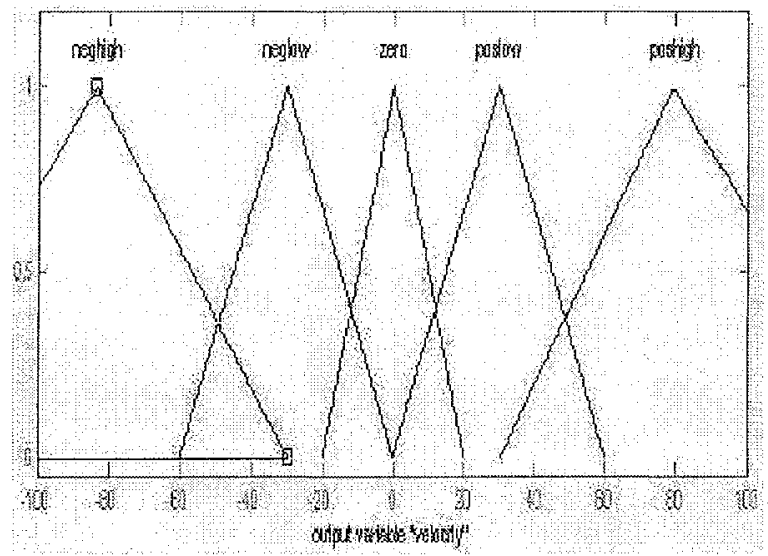

(c)

FIGURE-3: COMPLETE SET OF MEMBERSHIP FUNCTIONS WITH THEIR FUZZY LEVELS. 
Depending upon the Fuzzy Levels selected for the inputs and output appropriate rules can be generated. Some of which are,

1) If angle is zero and rate of change of angle is negative high then next required velocity is positive high.

2) If angle is positive and rate of change of angle is positive high then next required velocity is negative high.

The Mamdani type Fuzzy Controller is designed in FIS Editor and then exported to workspace for simulation purpose. The system of inverted pendulum is simulated in MATLAB SIMULINK as shown in Figure-4. The Fuzzy Logic Controller of simulink uses the 'ffis' file from the workspace.

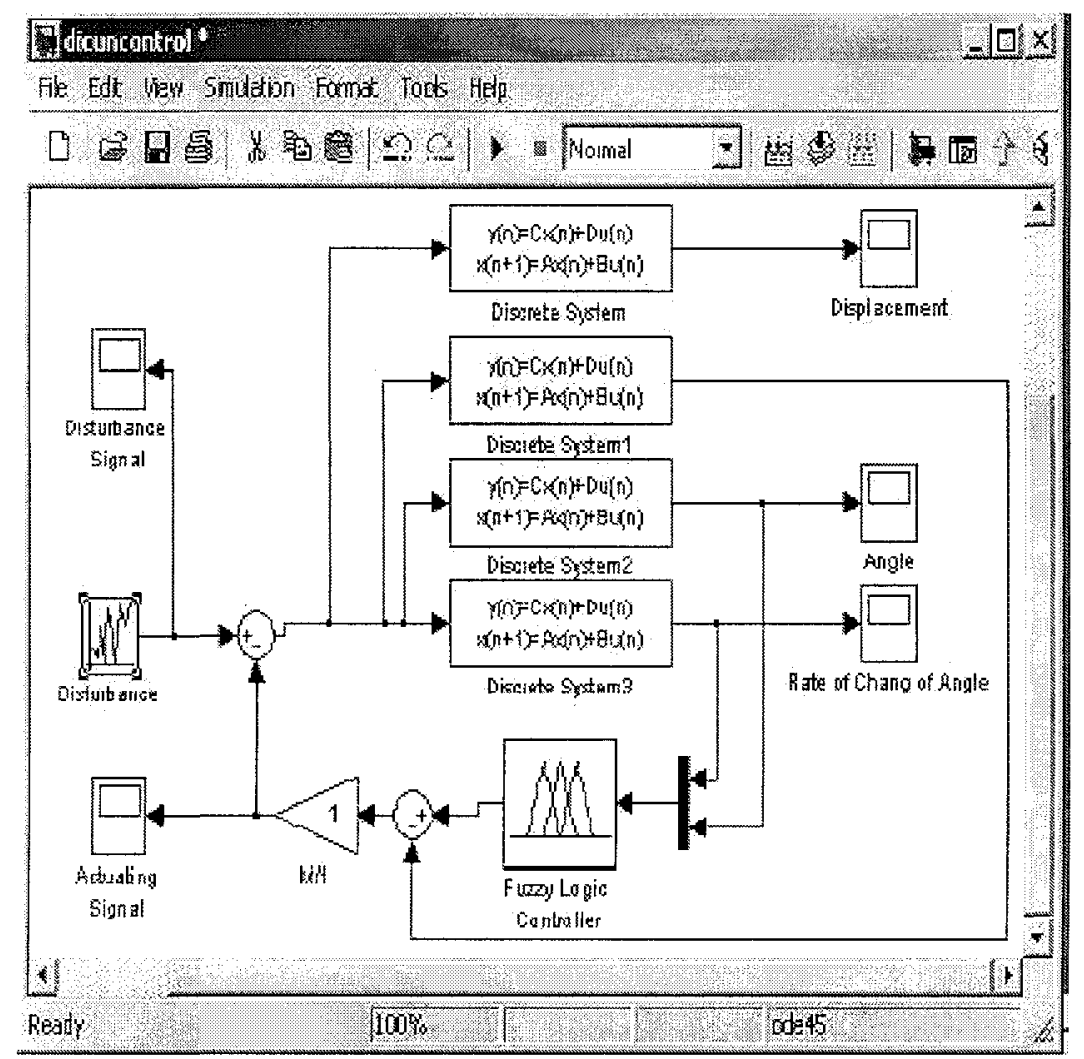

FIGURE-4: SIMULATION IN MATLAB

The simulation results along with disturbance input are taken which are as shown in following figures. 


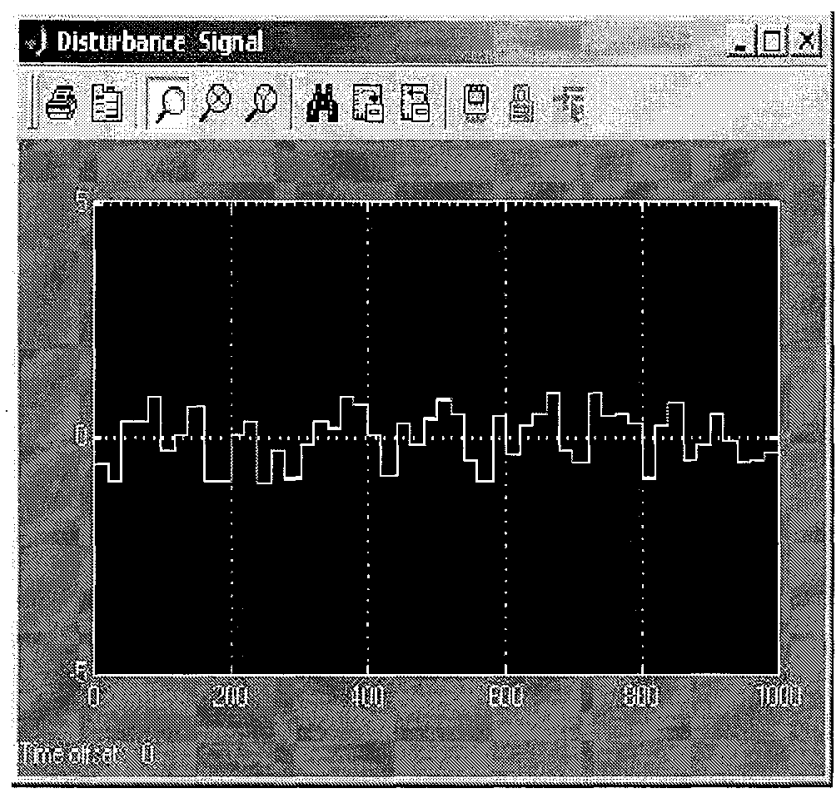

(a)

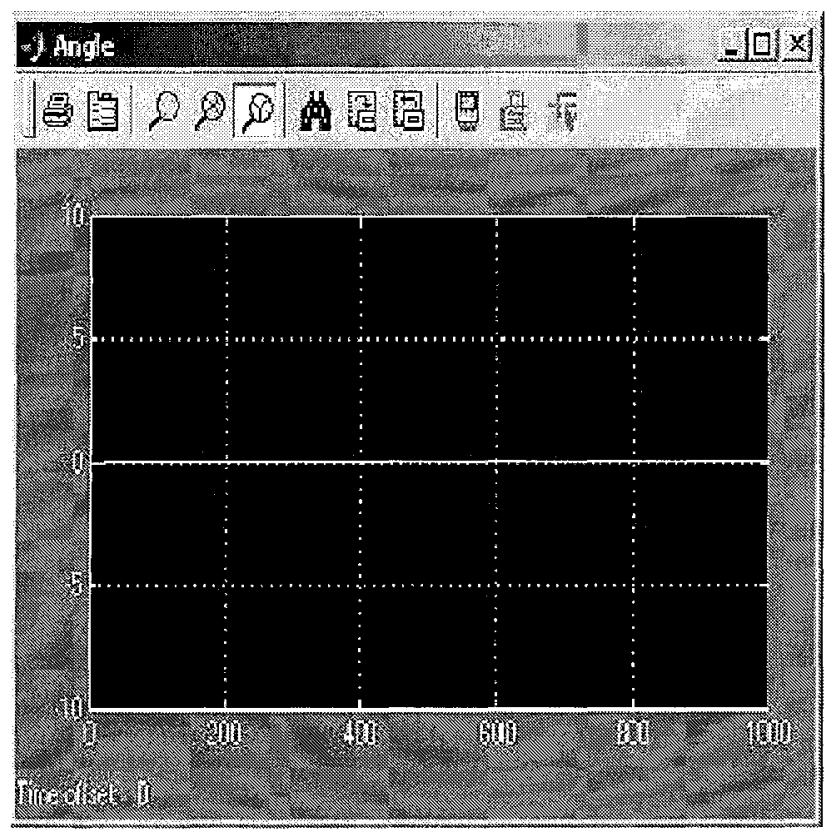




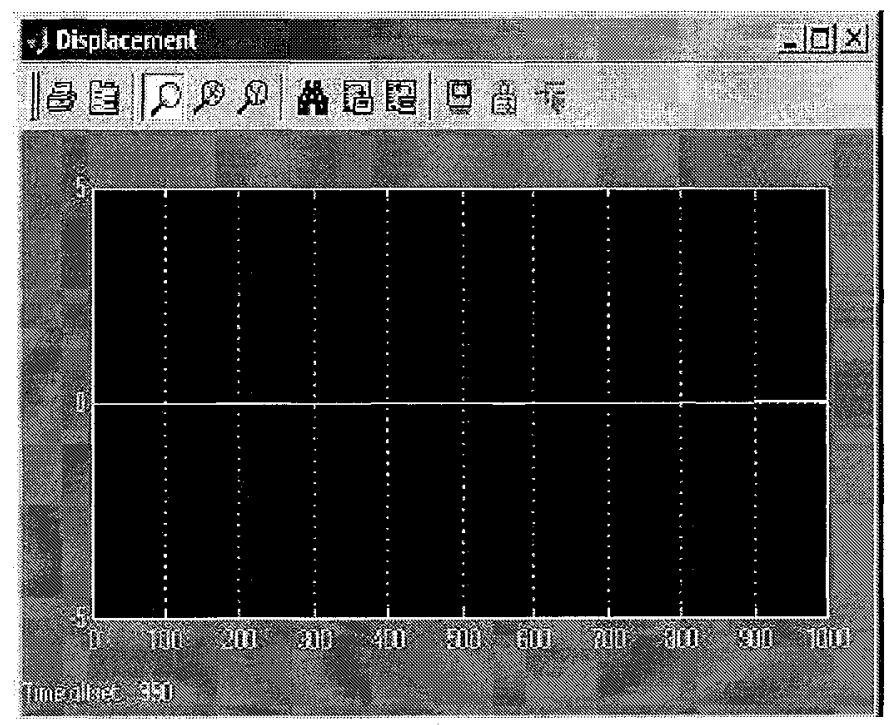

(c)

FIGURE-5: RESULTS

\section{CONCLUSION}

The next required velocity can be predicted from two inputs i.e. angle and rate of change of angle for that we have to design predictor. Predictor cannot be designed without facing mathematical complexities. Here, we tried to propose a non-mathematical approach to obtain next required velocity using fuzzy logic approach, which is used to obtain actuating signal to control the system. Problem of Inverted Pendulum is used as the test-bed to verify the effectiveness of the methodology and satisfactory results are obtained.

\section{ACKNOWLEDGEMENT}

The guidance and help of Prof. S. K. Shah (Faculty of Technology \& Engineering, M.S.University of Baroda) is gratefully acknowledged.

\section{REFERENCES}

[1] Fuzzy Logic Toolbox of MATALAB 6.5.

[2] M.Gopal, E(1997). " Digital Control and State Variable Methods".

[3] Fene F. Franklin and J. David Powell. " Digital Control of Dynamic Systems. 